\title{
Bargaining in the Absence of Property Rights: An Experiment
}

\author{
Oren Bar-Gill Harvard University \\ Christoph Engel Max Planck Institute for Research on Collective Goods
}

\begin{abstract}
The Coase theorem posits that if (1) property rights are perfect, (2) contracts are perfectly enforceable, (3) transaction costs are zero, (4) preferences are common knowledge, and (5) parties are rational, then the initial allocation of entitlements matters only for distribution, not for efficiency. We study, in an experimental setting, whether condition 1 is necessary. Our results suggest that property rights have a limited effect on efficiency.
\end{abstract}

\section{Introduction}

The Coase theorem (Coase 1960) states that if (1) property rights are perfect, (2) contracts are perfectly enforceable, (3) transaction costs are zero, (4) preferences (valuations) are common knowledge, and (5) parties are rational, then the initial allocation of property rights matters only for distribution, not for efficiency. Through ex post bargaining, the asset ends up with the individual who values it most highly (for a survey of the literature, see Korobkin [2014]). We challenge the necessity of condition 1 and ask, Does the Coase theorem require absolute property rights, that is, in rem rights against any nonowner (condition 1) ${ }^{1}$ Or are relative property rights-rights only against other parties to a contract (condition 2)-sufficient?

A game-theoretic analysis suggests that relative property rights are sufficient (compare Kaplow and Shavell 1996). This analysis critically depends on condition 5-that parties are rational and, moreover, that they have standard "homo economicus" preferences. Under these assumptions, efficiency always obtains, with

Helpful comments by Stefan Bechtold, Richard Brooks, Christopher Buccafusco, Gary Charness, Louis Kaplow, Russell Korobkin, Pedro Robalo, Paul Schempp, Steve Shavell, Dan Simon, Holger Spamann, Kathy Spier, Christopher Sprigman, Alexander Stremitzer, Eric Talley, Tess WilkinsonRyan, Fabian Winter, Kathryn Zeiler, and participants at the 2015 Experimental Methods in Legal Scholarship workshop (University of California, Los Angeles), the Max Planck Institute for Research on Collective Goods, and the 2015 Conference on Empirical Legal Studies are gratefully acknowledged.

${ }^{1}$ We use the terms "absolute property rights" and "property" interchangeably.

[Journal of Law and Economics, vol. 59 (May 2016)]

(c) 2016 by The University of Chicago. All rights reserved. 0022-2186/2016/5902-0016 $\$ 10.00$ 
or without absolute property rights. We experimentally test whether the equivalence between absolute and relative rights holds when condition 5 is relaxed, namely, when behavioral forces are introduced. We call this the equivalence hypothesis. (The introduction of behavioral forces also puts pressure on condition 4. While we can experimentally ensure common knowledge of standard preferences and valuations, the experimental setting allows for imperfect information about nonstandard preferences, such as fairness preferences. $)^{2}$

In the textbook version of the Coase theorem (with condition 1), the main challenge to efficient allocation arises when the good is initially allocated to the lower-valuation user. Efficiency requires that the higher-valuation user buy the good from its initial owner. In our version of the theorem, with no absolute property rights, the challenge to efficient allocation is different: in the absence of property, even if the good is initially allocated to the higher-valuation user, it might be taken by the lower-valuation user. Efficiency requires that the higher-valuation user acquire a contractual right that would prevent the lower-valuation user from exercising her right to take. Is Coasean bargaining equally efficient in both versions? Or do the behavioral forces cause greater interference in our version of the theorem with only relative rights?

If relative property rights and absolute property rights are equivalent, the higher-valuation user must be similarly willing to buy the good from the individual with lower valuation (absolute right) and to pay for the other individual not to take her good (relative right). This is what we test with our first treatment. Ultimately, in a world without property, taking is pointless. The original possessor could always take the good back, and so forth (see Kaplow and Shavell 1996). In such a world, the only technology for creating value is contract. We capture this dimension of the distinction between absolute and relative rights in our second treatment, in which the good is destroyed unless the parties agree on secured possession. We find that, irrespective of treatment, trade occurs in about 75 percent of cases. Neither treatment affects efficiency. We also do not find a significant difference in the price that the low-valuation individual asks when selling the good, refraining from taking the good, or agreeing that the good should not be destroyed. The equivalence hypothesis is supported by the data.

One might object that our experimental design undermines the difference between absolute and relative property rights. Participants might see the good as a pretext for a bargaining experiment, or they might view the initial allocation of the good to one party as normatively irrelevant. In two complementary ways, we investigate whether this objection is critical. First, we add a treatment in which we refer to taking as stealing. This framing manipulation has no discernible effect. Second, we have the initial possessor earn the good in a real-effort task. This

\footnotetext{
${ }^{2}$ The few experimental papers that study Coasean bargaining with imperfectly protected property rights focus on other conditions: Cherry and Shogren (2005) focus on condition 3 and introduce transaction costs, whereas Croson and Johnston (2000) and Ayres (2005) focus on condition 4 and study the effects of asymmetric information. Aivazian, Callen, and McCracken (2009) also find an effect of ill-defined property rights in situations in which the group is larger than two and no property rights are assigned.
} 
has a small, weakly significant negative effect on the probability that the good trades. If we combine the earning and the framing manipulations, takers demand less (but still more than 50 percent of the value of the good), yet the probability of trade remains unaffected.

Our research question is practically relevant. Many valuable assets are not legally protected. Must a neighbor accept vibrations, noise, or smell? Legal systems differ in where they draw the line, that is, in the way they define and enforce neighbors' property rights. But a contract in which one neighbor promises not to use her land in a way that would be perfectly legal is always enforceable. ${ }^{3}$

The remainder of the paper is organized as follows: Section 2 derives hypotheses from theory and from the existing experimental literature. Section 3 introduces the design of the experiment. Section 4 reports results from the main experiment. Section 5 reports on the framing manipulation. Section 6 discusses the earning manipulation. Section 7 concludes.

\section{Hypotheses}

\subsection{Setup}

Assume a society of size $N=2$. Individuals $\mathrm{H}$ and $\mathrm{L}$ are both endowed with $e$ units of a perfectly transferable, scalable, and protected means of payment. There is a single unit of a good. Without loss of generality, we assume that the value of this good to individual $\mathrm{H}$ is $v_{\mathrm{H}}>0$, and the value of the good to individual $\mathrm{L}$ is $v_{\mathrm{L}}=0$. Valuations are common knowledge. We further assume that $e>v_{\mathrm{H}}>$ $v_{\mathrm{L}}=0$, so that there is no budget constraint. Contracts are perfectly enforceable. Concluding and enforcing contracts are costless. The act of taking the good is similarly costless. Because $\mathrm{L}$ is allowed to make a take-it-or-leave-it offer, $\mathrm{L}$ has all the bargaining power.

\subsection{Standard Theory}

If individuals hold standard preferences, which are common knowledge, and there are no transaction costs, then the efficient outcome is always reached as long as contracts are enforceable. In the textbook version of the Coase theorem, in which the good is initially allocated to party L and L's entitlement is protected with a property rule, $L$ sells the asset to $H$ for $v_{\mathrm{H}}[-\varepsilon]$. In our version of the theorem, in which the good is initially allocated to party $\mathrm{H}$ but H's entitlement is not protected, $\mathrm{L}$ threatens to take, and $\mathrm{H}$ and $\mathrm{L}$ sign a contract, by which $\mathrm{H}$ pays $\mathrm{L}$ a bribe of $v_{\mathrm{H}}[-\varepsilon]$ and L commits not to take. From a standard game-theoretic perspective, the textbook version of the theorem and our version are indistinguishable. Therefore, our null hypothesis reads as follows:

\footnotetext{
${ }^{3}$ One may also draw an analogy to the law of adverse possession. If the statutory period has elapsed, in law the disseisor is the owner. If she values the piece of land less than the original owner, the efficient outcome (the original owner gets the land back) can obtain only through Coasean bargaining. Strictly speaking, this is an application of the textbook version of the Coase theorem. But it shares a flavor of our version of the theorem in that the right not to give the land back could be interpreted as legalized squatting.
} 


\section{Hypothesis 0. \\ a) The asset always ends up with $\mathrm{H}$. \\ b) Individual $\mathrm{H}$ pays $v_{\mathrm{H}}[-\varepsilon]$.}

\subsection{Behavioral Qualifications}

We adopt a simple bargaining protocol: $\mathrm{L}$ makes an offer, and $\mathrm{H}$ decides whether to accept or reject the offer. In describing possible behavioral effects, it is useful to address these two stages in reverse order.

First, what is the maximum amount that $\mathrm{H}$ would be willing to pay? This maximum amount constitutes H's reservation price, which we denote $R$. In the game-theoretic analysis, $R=v_{\mathrm{H}}$. In a behavioral model, H's reservation price includes additional dimensions. Consider the standard version of the Coase theorem, in which the good is initially allocated to party L and L's entitlement is protected with a property rule. The maximal amount that $\mathrm{H}$ would be willing to pay to purchase the good from $\mathrm{L}$ is affected by H's preferences for fairness. ${ }^{4}$ Formally, let $x$ denote the strength of H's fairness concerns. The maximal amount that $\mathrm{H}$ would be willing to pay, in this behavioral model, is $R=v_{\mathrm{H}}-x$. Next, consider our version of the Coase theorem, in which the good is initially allocated to party $\mathrm{H}$ but H's entitlement is not protected. Here, in addition to standard fairness concerns, a heightened fairness concern, reflecting a reluctance to pay for what is aleady mine, may further reduce H's reservation price $R .{ }^{5}$ Let $y$ denote this additional behavioral effect. We thus have $R=v_{\mathrm{H}}-x-y$.

We now turn to L: what amount will $\mathrm{L}$ offer? A perfectly rational (and riskneutral) L who seeks to maximize her absolute monetary payoffs will try to predict $R$ and make an offer that maximizes the expected payment (magnitude of the offer multiplied by the probability of acceptance). In the standard version of the theorem, L would form a prediction: $\hat{R}=v_{h}-\hat{x}$, where $\hat{x}=x+\varepsilon_{x}$ and the error term $\varepsilon_{x}$ is distributed according to the cumulative distribution function $F\left(\varepsilon_{x}\right)$. Then $\mathrm{L}$ would offer an amount $m$ that maximizes $\operatorname{Prob}(m \leq \hat{R}) \times m$, or $\operatorname{Prob}\left(\varepsilon_{x}\right.$ $\left.\leq v_{\mathrm{H}}-x-m\right) \times m$. With this chosen value of $m$, there is a probability $\operatorname{Prob}\left(\varepsilon_{x}\right.$ $\left.\geq v_{\mathrm{H}}-x-m\right)$ that efficient trade will not occur. In our version of the theorem, L's prediction of H's reservation price is $\hat{R}=v_{h}-\hat{x}-\hat{y}$, where $\hat{y}=y+\varepsilon_{y}$ and the error term $\varepsilon_{y}$ is distributed according to the cumulative distribution function

\footnotetext{
${ }^{4}$ As an entire literature on ultimatum games demonstrates, offers deemed grossly unfair are often rejected (Güth, Schmittberger, and Schwarze 1982; Oosterbeek, Sloof, and van de Kuilen 2004; Hoffman, McCabe, and Smith 2008; Cooper and Dutcher 2011).

${ }^{5}$ An endowment effect, driven by loss aversion, may also change H's reservation price (Kahneman, Knetsch, and Thaler 1991; Tversky and Kahneman 1991; Thaler et al. 1997; Köszegi and Rabin 2006). Indeed, loss aversion may increase H's reservation price $R$. Other explanations for an endowment effect (Kahneman, Knetsch, and Thaler 1990, 1991; Rachlinski and Jourden 1998; Tversky and Griffin 2000; Korobkin 2003) are ruled out by our experimental design. We use a simple token, and no endowment effect has been found with tokens (Kahneman, Knetsch, and Thaler 1990). Attachment, which is one potential source of the endowment effect, is unlikely to form with tokens (compare Kelman 1978-79; Brosnan et al. 2007). And regret, another potential source of the endowment effect, is unlikely to be triggered, since the token is originally assigned by the experimenter (compare Gilovich and Medvec 1995).
} 
$G\left(\varepsilon_{y}\right)$. In this case, $\mathrm{L}$ would offer an amount $m$ that maximizes $\operatorname{Prob}(m \leq \hat{R}) \times m$, or $\operatorname{Prob}\left(\varepsilon_{x}+\varepsilon_{y} \leq v_{\mathrm{H}}-x-y-m\right) \times m$. With this chosen value of $m$, there is a probability $\operatorname{Prob}\left(\varepsilon_{x}+\varepsilon_{y} \geq v_{\mathrm{H}}-x-y-m\right)$ that efficient trade will not occur. In both cases, the source of the inefficiency is prediction error, and the likelihood of bargaining failure increases in the variance of the error distributions $F\left(\varepsilon_{x}\right)$ and $G\left(\varepsilon_{y}\right)$ (compare Bebchuk 1984). But in our version of the theorem, L needs to estimate two variables, $x$ and $y$, whereas there was only a single variable to estimate in the standard version. Prediction thus becomes more difficult, and prediction error and inefficiency become more likely. Note also that the introduction of a new variable $y$ that reduces the reservation price $R$ reduces L's optimal offer $m$.

Furthermore, in our version of the theorem, disjunction between bargaining power and the initial allocation of the good might further increase the likelihood of prediction error. In the standard version of the theorem, the same party, L, both gets the good and enjoys all of the bargaining power. In our version, bargaining power is allocated to one party, L, while the good is initially allocated to the other party, H. Is L entitled to a larger share of the surplus, since she was granted all the bargaining power? Is $\mathrm{H}$ entitled to a larger share of the surplus, since the good was initially allocated to him? What is the relative strength of these competing claims? Here L would be uncertain about how $\mathrm{H}$ resolves these issues, and this uncertainty increases the likelihood of prediction error and inefficiency.

We have thus far assumed a perfectly rational $\mathrm{L}$ who seeks to maximize her absolute monetary payoffs. How does the analysis change when $\mathrm{L}$ is a behavioral actor? In the standard version of the theorem, the only behavioral effect involves fairness concerns. We have seen the implications of H's fairness concerns. But $\mathrm{L}$ may herself care about fairness. And this could reduce the amount that $\mathrm{L}$ demands and thus the likelihood of an inefficient failure to trade. In our version of the theorem, there is a second behavioral effect: a heightened fairness concern pushes H's reservation price further downward. But, in addition, L herself may be averse to taking, perceived as stealing. Experiments find (limited) hesitance to steal (Falk and Fischbacher 2002; Schildberg-Hörisch and Strassmair 2012; Engel and Nagin 2015; see also Prudencio 1982; Lewinsohn-Zamir 2012). And this hesitance could reduce the amount that L demands and thus the likelihood of an inefficient failure to trade.

In both situations-the standard version of the theorem and our versionthere is a behavioral effect (or more than one) that pushes H's reservation price downward and a corresponding effect that pushes L's offer downward. We expect the effect on H's reservation price to be stronger than the effect on L's offer: $\mathrm{H}$ being left with a smaller share of the surplus would likely be more painful to $H$ than it would be to L. Similarly, the loss that $\mathrm{H}$ experiences from taking, perceived as stealing, would likely be more painful to $H$ than to $L$. In this case, $L$ may not be aware of this asymmetry since she suffers from self-serving bias (see Loewenstein et al. 1993; Babcock and Loewenstein 1997; Haisley and Weber 2010). Or she may mispredict the degree of the asymmetry. Hence, even if $\mathrm{L}$ also holds social preferences, there is room for inefficiency. 
We stress that our experiment is not meant to test a particular behavioral theory or to discriminate between different behavioral effects. All we need, and all we test, is the prediction that in our version of the theorem the likelihood of a successful bargain is lower and L's offer is lower, for one of the potential behavioral reasons that we have discussed or some combination of them. In particular, we test the following alternative hypothesis:

\section{Hypothesis 1.}

a) Individual $\mathrm{H}$ does not always obtain the good.

b) Bargaining failure is more frequent if $\mathrm{H}$ does not have a property right in the good.

c) The price demanded by $\mathrm{L}$ is lower if $\mathrm{H}$ does not have a property right in the good.

\section{Design}

Our baseline is the textbook version of Coase's theorem: an individual with low valuation for a good (which we fix at 0) holds an absolute right in the good. The individual with high valuation may buy the good from her.

We compare this baseline with two treatments. Each treatment is meant to capture a different potential downside of not protecting property. The first treatment, Take, tests the willingness of the high-valuation user to pay for the lowvaluation user not to take the good. To test this key aspect of the theorem, we simplify the situation. We initially assign the good to the high-valuation user and make it possible for the low-valuation user to take the good.

The first version of the experiment allows for only one possible taking (by the low-valuation user). In theory, in the absence of property rights, the highvaluation user would be able to take the good back, the low-valuation user would be able to take again, and so on (Kaplow and Shavell 1996). Given the possibility of reciprocal takings, the good is worthless in the absence of a contract. Any value requires a contract. To capture this aspect of the theory, we conduct a second version of the experiment, the Destroy treatment. In this version, the experimental protocol provides for the destruction of the good unless the parties conclude a contract. One may also say that, in this treatment, participants bargain over the right to undisturbed use. While this protocol captures the reciprocal takings problem implied by the absence of property, one may wonder whether it has additional behavioral implications. Each version of the experiment thus captures a separate dimension of bargaining in the absence of an absolute property right.

The examples from legal practice listed in Section 1 map more directly to the Take treatment: a neighbor may annoy me with her noise, smell, or vibrations (and thereby appropriate some of the enjoyment of my land). But there are also illustrations that are closer to the Destroy treatment. Not so rarely, a good has value only as long as it is unique. A classic illustration is a secret. If somebody else knows my secret, or is able to learn it, it becomes worthless unless the parties are able to reach a contractual arrangement. Another person may also have naked 
threat power because she is able to (legally) inflict harm on me, say, by exercising a right that has no intrinsic value to her. Divorced parents fighting over the right to live with their child might be taken as an illustration of a feud that destroys what both hopefully care most about: their child's well-being.

\subsection{Baseline and Treatments}

\subsubsection{Baseline}

In the Baseline treatment, a token good is originally assigned to individual L. If, at the end of the experiment, $\mathrm{L}$ is still in possession of the good, the good has $v_{\mathrm{L}}=$ 0 . If, by contrast, $\mathrm{H}$ possesses the good, the experimenter buys the good at $v_{\mathrm{H}}<$ $e$. Property is perfectly protected, which means that the only way for $\mathrm{H}$ to possess and use the good is by concluding a contract with $\mathrm{L}$, who is allowed to make a take-it-or-leave-it offer. The parties are free to choose any price $\in[0, e]$. If a deal is struck, the good is transferred to $\mathrm{H}$; $\mathrm{L}$ receives the price. There are no negotiation or enforcement costs and no time limit.

\subsubsection{The Take Treatment}

In the Take treatment, we assign the token good to individual $\mathrm{H}$ at stage 1 . At stage 3, individual L can unilaterally take the good from individual H. At stage 2, before individual $\mathrm{L}$ gets the chance to unilaterally take the good, the parties can bargain, and individual L may commit not to take the good. The bargaining protocol is as follows: individual L makes a take-it-or-leave-it offer to individual $\mathrm{H}$. There are no negotiation or enforcement costs and no time limit. If a contract is reached, the good stays with individual $\mathrm{H}$ and the game ends (we do not proceed to stage 3 ). If a contract is not reached, we proceed to stage 3 , and individual $\mathrm{L}$ decides whether to take the good. And then the game ends. If individual $\mathrm{H}$ possesses the good at the end of the experiment, she receives her redemption value $v_{\mathrm{H}}$ from the experimenter. If individual $\mathrm{L}$ possesses the good at the end of the experiment, she receives her redemption value $v_{\mathrm{L}}=0$ from the experimenter.

\subsubsection{The Destroy Treatment}

In the Destroy treatment, the good is originally assigned to individual $\mathrm{H}$ at stage 1 . Property is not protected, which means that $\mathrm{L}$ is free to take the good or to threaten to do so. The only way for $\mathrm{H}$ to secure possession and use of the good is by concluding a contract with $\mathrm{L}$. At stage $2, \mathrm{~L}$ is allowed to make a takeit-or-leave-it offer. If $\mathrm{H}$ rejects, the good is not protected. If a deal is struck, one of the parties gains secure possession; the other receives a price. There are no negotiation or enforcement costs and no time limit. In order not to artificially constrain the negotiation space, contracts that give the good to L are permitted. At the end of the experiment, the good is bought by the experimenter at its redemption value, but only if the parties concluded a contract.

In our model, the good could go endlessly back and forth between the two par- 
Table 1

Comparison of Treatments

\begin{tabular}{lccc}
\hline & Baseline & Take & Destroy \\
\hline Original good allocation & L & H & H \\
Property right & Yes & No & No \\
Bargaining power & L & L & L \\
Effect of bargaining failure & Good stays with L & L may take good & Good is destroyed \\
\hline
\end{tabular}

ties as long as no contract has been concluded. Directly translating this into an experimental protocol would be impractical; participants know for sure that any experiment ends within a reasonable time. Other experiments have created quasi infinity by a rule that the experiment in every period ends (after a sequence of initial periods) with a small probability. But if we had used that design option, there would have been more than one difference between this and the Take treatment: one shot versus repeated (with uncertain end) and a single option versus the option to take and to take back. Yet the critical element of the model is not the actual taking and possible taking back. The critical element is that, in the absence of a contract, the good is worthless. This we implement by the following rule: if $\mathrm{L}$ does not make an offer, or if $\mathrm{H}$ rejects the offer, the good is destroyed. ${ }^{6}$ Table 1 summarizes our treatments.

\subsection{Motives for Design Choices}

We are interested in testing whether the textbook version of the Coase theorem and our alternative version yield different outcomes, despite the fact that standard theory predicts no difference. We therefore focus on a situation for which this theoretical equivalence holds. One might criticize this approach since theoretical equivalence requires two differences in design: presence versus absence of a property right and original assignment of possession to $\mathrm{L}$ versus $\mathrm{H}$. Yet if we change only one of these two features in isolation, standard theory predicts fundamentally different outcomes (at least for the Take treatment). For testing our hypothesis, we cannot change one of these elements in isolation. In essence, we are testing whether giving a property right to $\mathrm{L}$ is different from giving $\mathrm{L}$ the option to take the good from $\mathrm{H}$. Standard theory says that there is no difference. The behavioral analysis suggests several possible differences. (Even standard theory would predict a difference between the Take and Destroy treatments when $v_{\mathrm{L}}>$ 0 . But when individual $L$ values the asset at 0 , these differences disappear.)

In the field, individuals who value a good less usually do not regard the good to be completely worthless. In the interest of increasing external validity, it might therefore have been attractive to set $v_{\mathrm{L}}>0$. Yet in the Destroy treatment, the good is destroyed if there is no trade. We want to be in a position to compare the Baseline treatment with both the Take treatment and the Destroy treatment and

\footnotetext{
${ }^{6}$ Since the game remains one shot, we also have no reason to consider the possible additional complication resulting from the need to predict the timing preferences of the negotiation partner.
} 
Table 2

Time Lines of Experimental Treatments

\begin{tabular}{ll}
\hline Time & \multicolumn{1}{c}{ Description } \\
\hline$t_{1}$ & Groups are formed, valuations are assigned, and treatment conditions are defined \\
$t_{2}$ & Individual L, who has all the bargaining power, makes an offer \\
$t_{3}$ & Individual $\mathrm{H}$ decides whether she accepts \\
$t_{4}:$ & If a contract is made, the good is transferred to individual $\mathrm{H}$ \\
Baseline & If a contract is made, the good stays with individual $\mathrm{H}$ \\
Take & If a contract is made, the good either stays with individual $\mathrm{H}$ or is transferred to \\
Destroy & individual L \\
$t_{5}:$ & If a contract is not made, the good stays with individual $\mathrm{L}$ \\
Baseline & If a contract is not made, the taker decides whether to take the good from its \\
Take & current owner \\
Destroy & If a contract is not made, the good is destroyed \\
$t_{6}$ & The individual who eventually possesses the good sells it to the experimenter, at \\
& her valuation
\end{tabular}

the latter two treatments with each other. Now, if bargaining fails in the Baseline and Take treatments, $\mathrm{L}$ is still in possession of the good. Consequently, had we chosen $v_{\mathrm{L}}>0$, there would have been a confounding difference between the Destroy treatment and the remaining two versions of the experiment: a difference in payoffs in case negotiations fail $\left(v_{\mathrm{L}}>0\right.$ versus 0$)$. This confound would have prevented us from meaningfully comparing the different versions of the experiment. $^{7}$

\subsection{Timeline}

In both versions of the experiment, participants are randomly matched to groups of two. All are endowed with $e=40$ units of an experimental currency ECU. There is 1 unit of a good. Valuations for this good are randomly assigned. Individual $\mathrm{H}$ values the good at $v=30 \mathrm{ECU}$, and individual $\mathrm{L}$ values the good at $v=0$ ECU. Valuations are common knowledge. Table 2 presents the time line for all versions of the experiment.

${ }^{7}$ In the Take treatment, if the L player were exclusively motivated by money, she would be indifferent between taking and not taking the good in the case of bargaining failure, and thus the threat to take would be less credible. The $\mathrm{H}$ player would anticipate the indifference and reject offers when $\mathrm{L}$ demanded a high price to refrain from taking. Yet this is not what we observe: there is no significant difference between Baseline and Take or between Take and Destroy (where the negative effect on H's payoff is automatic). The likely reason is behavioral. Taking the good is a technology for punishing the $\mathrm{H}$ player for rejecting the offer. This punishing sentiment is a well-established behavioral regularity. It is observed, for example, in the ultimatum game when responders reject low offers (Cooper and Dutcher 2011). The data on bargaining and taking from our experiment are consistent with this behavioral explanation. In our Take treatments, bargaining is often successful, and when it fails, taking often occurs. Of the 144 bargaining games (across the four Take treatments), we observe 105 successful bargains; in 27 of the 39 cases in which bargaining fails, taking occurs. This suggests that $\mathrm{H}$ players considered L's threats to take credible, and correctly so. 


\subsection{Postexperimental Tests}

Our experiment tests for possible failures in Coasean bargaining and, especially, whether such failures are more frequent in the absence of property rights. The source of these possible bargaining failures lies in a series of behavioral regularities (see Section 2.3). To test whether these regularities affect choices in our bargaining game, within subjects we administer three incentivized postexperimental tests and a nonincentivized questionnaire. At the beginning of the experiment, participants learn only that the experiment has several parts but do not know what these parts are. That way, the results of the main experiment cannot be affected by the anticipation of later parts.

The first test is a standard ultimatum game (Güth, Schmittberger, and Schwarze 1982), with individual $\mathrm{L}$ in the role of proposer and individual $\mathrm{H}$ in the role of responder. Participants receive an endowment of 20 ECU. Groups are rematched into unannounced matching groups of six. This standard procedure is meant to guarantee independent observations without inducing participants to second-guess group composition (see, for example, Charness 2000; Montero, Sefton, and Zhang 2008).

The second test is a simple stealing game (Falk and Fischbacher 2002; Engel and Nagin 2015). Individual $\mathrm{H}$ is endowed with 1 unit of a good and is randomly paired with individual L (again from the same unannounced matching group), who may take the good. Whoever possesses the good at the end of this part of the experiment receives 20 ECU from the experimenter.

The third test is a standard instrument to measure social value orientation, the so-called ring measure (McClintock and Liebrand 1988). In a nonincentivized questionnaire, we administer the Big Five instrument (Rammstedt and John 2007), ask four questions measuring trust taken from the German SocioEconomic Panel, and ask for basic demographic information.

The Experimental Lab of the University of Hamburg's Economics Department was kind enough to run the experiment for us. The experiment was programmed using zTree (Fischbacher 2007). The instructions are provided in the online appendix. Participants were invited using hroot (Bock, Baetge, and Nicklisch 2014). As announced in the instructions, participants never learned with which other participant they interacted. Each treatment comprised 72 student participants with various majors, for a total of 216 participants, 116 (53.7 percent) of whom were female. Mean age was 25.58 years. The experiment lasted approximately 1 hour, and participants on average earned $€ 11.76$ ( $\$ 14.66$ at the time of the experiment, with a range of $€ 4.6-€ 21)$.

\section{Results of the Main Experiment}

\subsection{Treatment Effects}

Figure 1 displays the results. In the Baseline and Take treatments, the same number of offers is rejected (eight of 36). In the Destroy treatment, five of the 33 


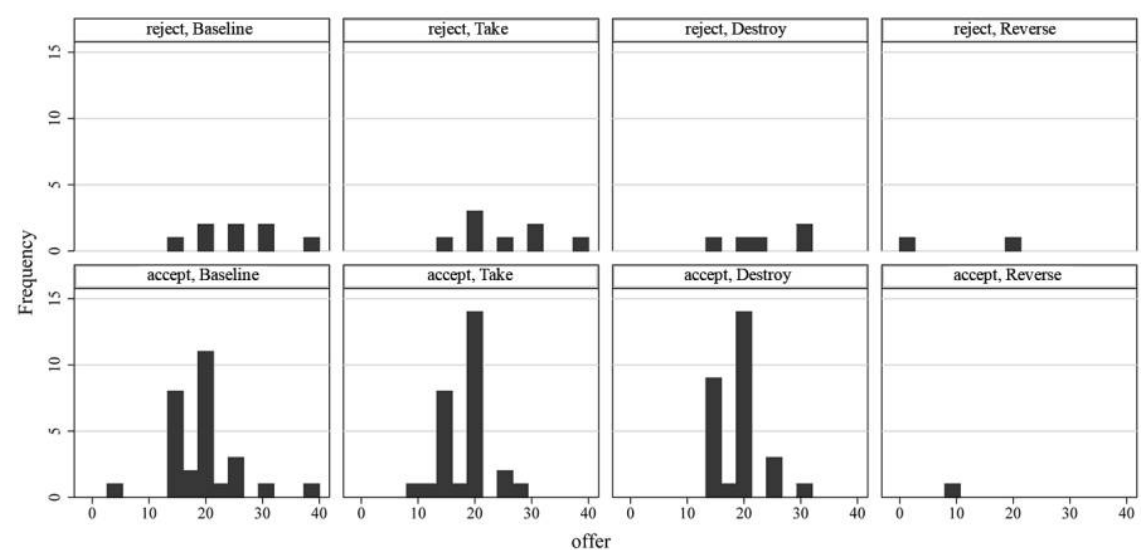

Figure 1. Frequency of offers and acceptance by treatment (and direction of transfer)

offers that propose to give the good to $\mathrm{H}$ are rejected, and in the Reverse treatment (where $\mathrm{L}$ get the good and pays a price to $\mathrm{H}$ ) two of the three offers are rejected. Given these numbers, we obviously do not find any significant treatment differences, whether we use nonparametric Mann-Whitney tests, estimate a parametric logit model, or include the offers (in the Destroy treatment) that propose to give the good to L. We also do not find any treatment differences if we condition the acceptance decision on the amount the L player requests. This rejects hypothesis $1 b$ and gives us the following result:

Result 1. Coasean bargaining is no less efficient in the absence of absolute property rights.

Strictly speaking, this result shows only that, with our data, we are not able to reject our null hypothesis of no treatment difference. This is not the same as showing that the null hypothesis is true. Power calculations indicate how much trust we can put in this nonresult. In each treatment, we have 36 independent observations. It is conventional to accept a $\beta$-error of .2. If we follow this convention, we can safely detect an effect of standardized size .6696. Since all of our hypotheses are directed, we are justified in using a one-sided test. We may therefore even safely conclude that we have not overlooked an effect of standardized size .5918 .

We see that offers also look very similar across treatments in Figure 1. Again, we do not find any significant differences, whether we use a nonparametric Mann-Whitney test or ordinary least squares regression or whether we include offers (in the Destroy treatment) that propose to give the good to L. ${ }^{8}$ This rejects hypothesis $1 c$ and gives us the following result:

${ }^{8}$ Since the sample size is the same as for testing the frequency of trade, the minimum standardized effect size we can safely detect is also identical: .6696 for a two-sided test or .5918 for a onesided test. 
Result 2. In the two versions of the Coase theorem, individual $\mathrm{L}$ makes indistinguishable price offers.

\subsection{Testing Standard Theory}

While we do not find any differences in the treatments, we also do not support our null hypothesis, which is based on standard theory. With common knowledge of rationality, we should not have found 77.78 percent (Baseline and Take treatments) or 84.85 percent (Destroy treatment if the good is to stay with $\mathrm{H}$ ) rates of acceptance; rather, the acceptance rate should be (close to) 100 percent. Using a binomial test, at conventional levels we can exclude that this probability is larger than 89 percent in the Baseline and Take treatments and larger than 90 percent in the Destroy treatment. ${ }^{9}$ This supports hypothesis $1 a$.

By the same token, with common knowledge of rationality, the mean offer should not have been 20.97 ECU in the Baseline treatment, 19.97 ECU in the Take treatment, or 19.03 ECU in the Destroy treatment. Rather, irrespective of treatment, the offers should have been close to $v_{\mathrm{H}}=30$, since the design gives $\mathrm{L}$ all of the bargaining power. Yet, using a one-sample signed-rank test, in the Baseline treatment we can exclude that the offer is larger than 22 ECU. ${ }^{10}$ In the Take and Destroy treatments we can exclude that the offer is larger than 20 ECU. ${ }^{11}$

\subsection{Explanations}

We do not find any differences by treatment, which suggests that behavioral forces do not play a meaningful, differential role in our setup; namely, they do not have a meaningfully different effect in our version of the theorem as compared with the standard version. Our findings do not support standard game-theoretic predictions either: behavioral forces play a role, just not a differential role. Revisiting Figure 1, we observe that offers giving L more than 20 are very likely to be rejected. Irrespective of treatment, offers peak at $15\left(v_{\mathrm{H}} / 2\right)$ and $20(e / 2)$. We turn to the data from our postexperimental tests to understand these findings.

The fact that we do not find differences in the treatments' offer amounts sheds light on the importance of the behavioral effects discussed in Section 2.3. In particular, the heightened fairness concerns and respect for ownership led us to hypothesize lower offers in the treatment (hypothesis $1 c$ ), and we do not find such lower offers. Results from the postexperimental stealing game show that respect for ownership did not play a meaningful role in our setup: only six of 108 partic-

\footnotetext{
${ }^{9}$ We avoid testing at the limit of the support by repeating the test of all probabilities between 75 percent and 99 percent and report the lowest percentage at which a two-sided test still rejects the null hypothesis at conventional levels.

${ }^{10}$ We face the same problem of testing at the limit of the support as with acceptance decisions, and we approach it the same way. We test whether the mean offer, in this treatment, is between 1 and 39 ECU. We report the highest value at which the test still rejects the null hypothesis: 23 ECU, $p=.0059$.

${ }^{11}$ The highest value at which the test rejects the null hypothesis is $21 \mathrm{ECU}, p=.0256$ in the Take treatment, and $p=.0085$ in Destroy treatment.
} 
ipants decided not to take the good in this game. (It would not be surprising to find minimal stealing in the postexperimental test and still find that loss aversion and respect for ownership reduce the offers in the Take and Destroy treatments: in the postexperimental stealing game, the taker gained positive value from taking the good, and this monetary incentive may have overcome any respect for ownership. In contrast, in the Take and Destroy treatments, the taker stood to gain nothing from taking. $)^{12}$

The postexperimental ultimatum game sheds further light on the importance of behavioral forces in our framework. This postexperimental test replicates results from previous experiments with ultimatums. Fairness norms prevent the offeror from making very high offers (namely, from keeping almost all of the surplus to himself). And some inefficiency results when the offeror thinks that an amount is sufficiently fair and the offeree thinks otherwise. These considerations affect the Baseline and the Take and Destroy treatments in the main experiment. Accordingly, they explain why results from our main experiment are not in line with standard game-theoretic predictions.

In Figure 2, offers in the ultimatum game are recoded as the share the proposer wants to keep for herself, to increase comparability between the main experiment and the postexperimental test. (The marker size indicates the frequency.) It is interesting that offer amounts in the ultimatum game do not significantly explain offer amounts in the main experiment-neither in the Baseline nor in the Take and Destroy treatments. This result holds whether we control for treatment in the main experiment and whether we interact treatment with the amount demanded in the ultimatum game. It seems that the bargaining game-ultimatum versus Baseline versus Take and Destroy treatments-has an effect on how fairness norms manifest but that this effect is not systematic; it varies among individuals. We do not find any significant effects when attempting to explain choices with data from the ring measure of social values or from the questionnaire.

\section{The Frame Treatment}

As a first robustness check, we repeat the Take treatment from the main experiment but now refer to taking as stealing. This Frame treatment was conducted in the same lab with the same software. We had 66 new participants, ${ }^{13}$ half of whom assumed the role of $\mathrm{H}$ and half of whom assumed the role of $\mathrm{L} ; 48.48$ percent were female, and the mean age was 25.03 years. Participants on average earned $€ 15.19$.

\footnotetext{
${ }^{12}$ We find more stealing than is common in the literature (see, for example, Schildberg-Hörisch and Strassmair 2012). This is likely because we present subjects with a binary choice-steal (you get everything and the other party gets nothing) or not steal (you get nothing and the other party gets everything). Other experiments involving stealing allow for a continuous stealing decision-the subjects decide how much to steal.

${ }^{13}$ In one of the three sessions, so many invited participants did not show up that we could not fill one matching group of six participants.
} 


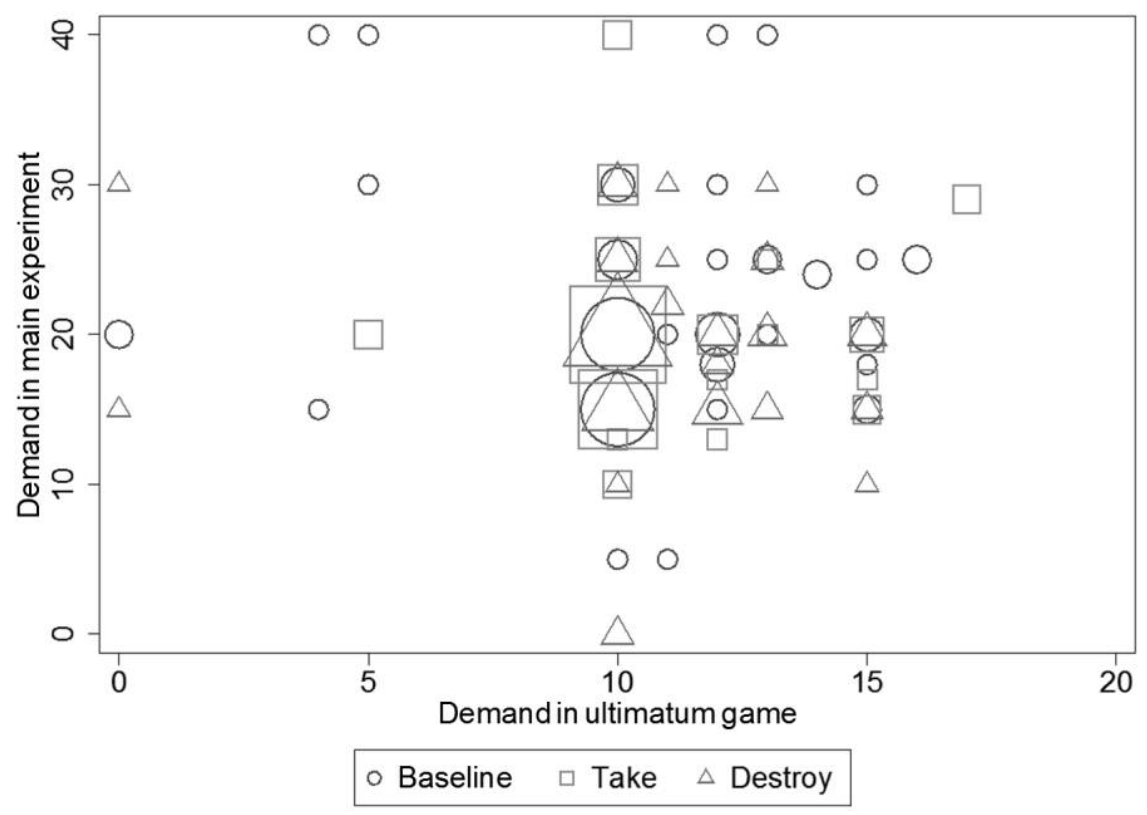

Figure 2. Offers in the main experiment and the ultimatum game

Figure 3 compares the Take treatment without and with the stealing frame. If we add the frame, we see that a few more deals fail (63.64 percent of all goods trade, rather than 77.78 percent without the frame). Yet this difference is not significant whether we use a nonparametric Mann-Whitney test or a logistic regression or whether we control for or interact with the size of the offer. The mean amounts demanded by player L are virtually identical (19.97 in the Take treatment versus 20.00 in the Frame treatment). Unsurprisingly, we do not find any statistical difference regarding the amount requested, neither nonparametrically nor parametrically. Of course, these are again only null effects. But we have enough statistical power to detect an effect of standardized size .6851 in a twosided test and .6054 in a one-sided test. ${ }^{14}$

\section{Earned Good}

In the final robustness check, whoever initially receives the good has to earn it. We use a simple but annoying real-effort task (as used, for instance, in Falk and Huffman [2007]): the participant has to correctly count the number of ones in 10 tables of $10 \times 10$ with ones and zeroes. With this change we repeat the Baseline, Take, and Frame treatments. These additional experiments were conducted in the

\footnotetext{
${ }^{14}$ Power differs (slightly) from calculations in the main experiment since we had six fewer participants (three responders) in the Frame treatment.
} 


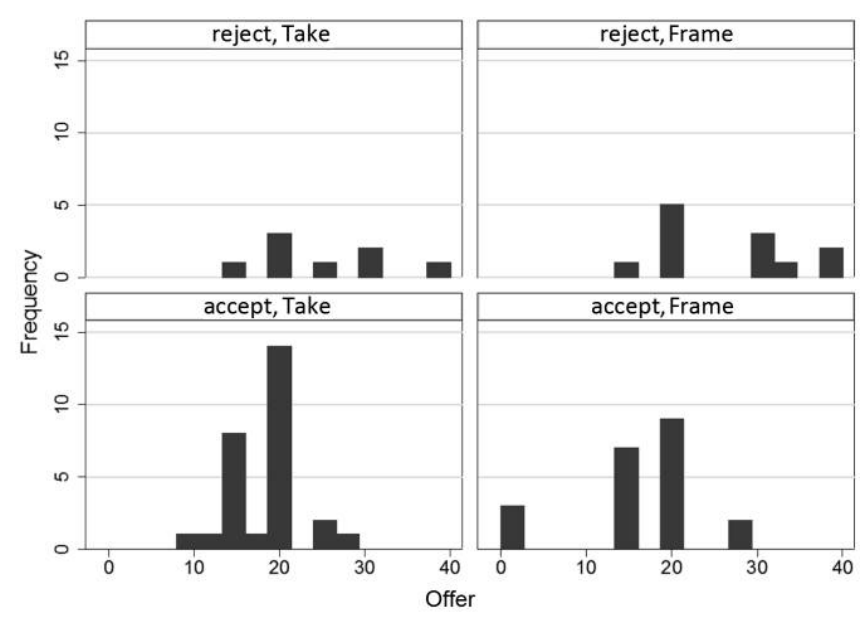

Figure 3. Take versus Frame treatments, with the good assigned by the experimenter

same lab using the same software. ${ }^{15}$ We had 204 new participants, 59.80 percent of whom were female. Mean age was 25.39 years, and participants on average earned $€ 15.63$.

As Figure 4 shows, this manipulation changes outcomes, but only slightly. If the good is assigned (in the main experiment), 77.78 percent of all goods trade in the Baseline and Take treatments, and 63.64 percent trade in the Frame treatment. In the Earned Baseline treatment, even more goods trade (83.33 percent), while fewer goods trade in the Earned Take treatment (63.64 percent). The comparison between the Earned Baseline and Earned Take treatments is the only weakly significant effect (Mann-Whitney test; $N=69, p=.0646$ ). We are reluctant to read too much into this result, since the size of the offer in the Earned Take treatment (19.52 ECU) is not significantly different from that in Earned Baseline treatment (20.78 ECU). Moreover, all other comparisons of accepted offers are insignificant whether we use nonparametric or parametric statistics or either control for or interact with the size of the offer. Note in particular that even more goods (78.79 percent) trade if the good is earned and the taking manipulation is combined with the Frame treatment.

This is all the more remarkable since we do find a significant effect on the size of the offer in the Earned Frame treatment. The average offer size in the Earned Frame treatment is 17.91 ECU, as compared with 20.78 ECU in the Earned Baseline treatment-a statistically significant difference (Mann-Whitney test; $N=$ $69, p=.0028)$. The Earned Frame treatment puts our hypothesis to the hardest test. The results suggest that proposers are sensitive to these manipulations. They

\footnotetext{
${ }^{15}$ We do not repeat the Destroy treatment since it did not significantly differ from the Take treatment in the main experiment. In the Earned Take and Earned Frame treatments, we were unable to fill one matching group of six participants each.
} 


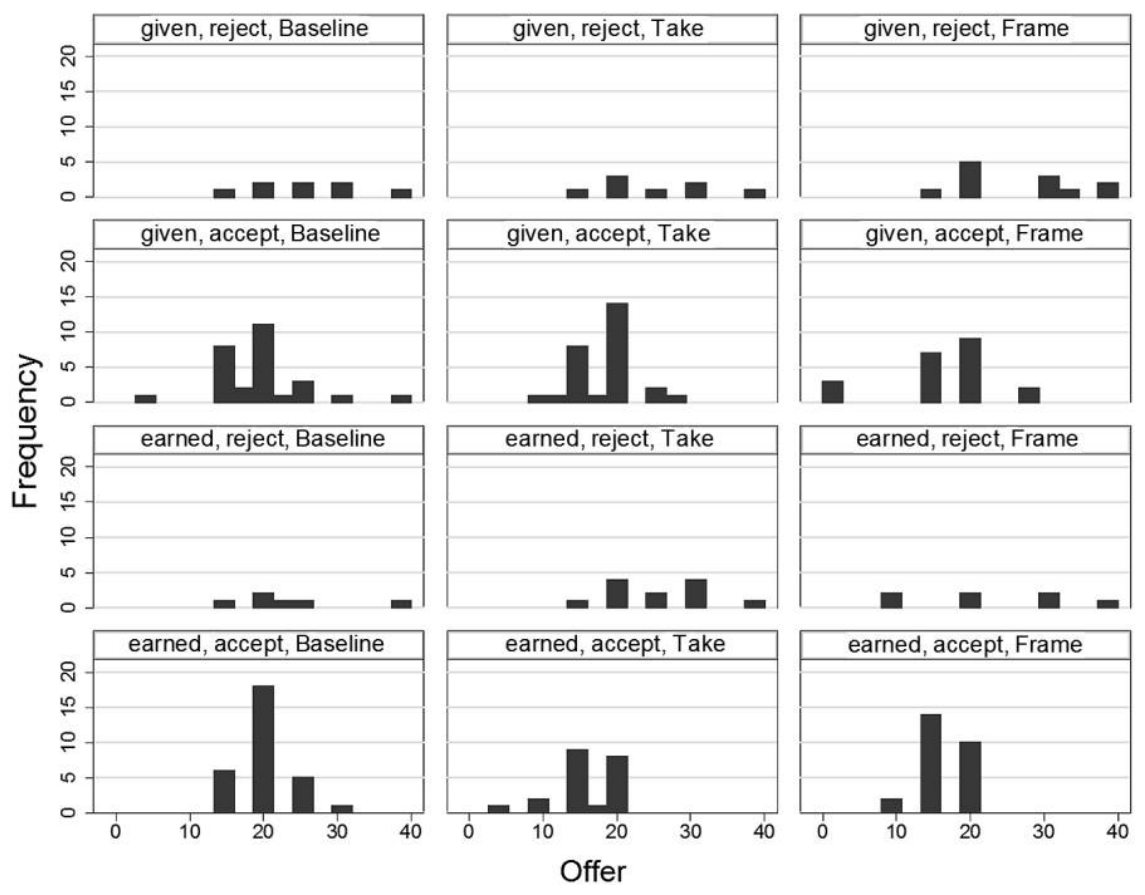

Figure 4. Choices in treatments with assigned versus earned goods

deem it fair to leave the other participant a larger share, but this share is on average still less than half the value of the good (which is 30). In terms of efficiency, making a lower offer does not result in more deals. It seems that proposers offer to leave possessors with a larger share because they accurately anticipate that possessors will have a higher reservation price in the Earned Frame treatment. And, in any event, we do not see fewer trades or more inefficiency, as in the Earned Take treatment.

\section{Conclusion}

Are absolute property rights necessary for efficient Coasean bargaining? Or are relative, contractual rights sufficient? In a rational choice, game-theoretic framework, efficiency obtains with both absolute and relative rights. In this paper, we show that bargaining is equally efficient when well-established behavioral regularities are taken into account.

To test whether behavioral effects are more detrimental to ex post bargaining in our version of the theorem, we compare three situations in the lab: there is an absolute property right, but it is initially allocated to the individual who values the good less (the standard version of the theorem-the Baseline treatment); the good is initially allocated to the individual who values it more, but the other in- 
dividual may take it at no cost (our version of the theorem-the Take treatment); if the two participants do not strike a deal, the good is destroyed (our version of the theorem-the Destroy treatment). We find no discernible difference between these three versions of Coasean bargaining, either in terms of efficiency or in terms of the price at which the individual with lower valuation agrees to assign the good to the other individual. Coasean bargaining is as effective with mere contractual rights as it is with absolute property rights.

This striking result obtains even if we frame taking as stealing. When the original possessor earns the good, we find a small reduction in the number of efficient trades. The robustness of this effect is, however, questionable. In particular, it disappears when taking is framed as stealing - a framing that would be expected to intensify the effect. In the Earned Frame treatment, we find a significant effect on the offered price: despite having all of the bargaining power, the potential taker leaves the person who originally earned the good a somewhat larger share. But this difference in the size of the offer does not seem to affect the number of trades.

This equivalence between absolute and relative rights refutes our behavioral hypothesis (hypothesis 1). We predicted that our version of the Coase theorem (with relative rights) would trigger additional behavioral effects and that these effects would increase strategic uncertainty and thus the incidence of bargaining failure. Our equivalence result suggests either that these additional behavioral effects are weak, relative to baseline fairness concerns, or that they are predictable (and thus do not substantially increase strategic uncertainty).

\section{References}

Aivazian, Varouj A., Jeffrey L. Callen, and Susan McCracken. 2009. Experimental Tests of Core Theory and the Coase Theorem: Inefficiency and Cycling. Lournal of Law and Economics 52:745-59.

Ayres, Ian. 2005. Optional Law: The Structure of Legal Entitlements. Chicago: University of Chicago Press.

Babcock, Linda, and George Loewenstein. 1997. Explaining Bargaining Impasse: The Role of Self-Serving Biases. Lournal of Economic Perspectives 11(1):109-26.

Bebchuk, Lucian Arye. 1984. Litigation and Settlement under Imperfect Information. RAND Journal of Economics 15:404-15.

Bock, Olaf, Ingmar Baetge, and Andreas Nicklisch. 2014. hroot: Hamburg Registration and Organization Online Tool. European Economic Review 71:117-20.

Brosnan, Sarah F., Owen D. Jones, Susan P. Lambeth, Mary Catherine Mareno, Amanda S. Richardson, and Steven J. Schapiro. 2007. Endowment Effects in Chimpanzees. Current Biology 17:1704-7.

Charness, Gary. 2000. Self-Serving Cheap Talk: A Test of Aumann's Conjecture. Games and Economic Behavior 33:177-94.

Cherry, Todd L., and Jason F. Shogren. 2005. Costly Coasean Bargaining and Property Right Security. Environmental and Resource Economics 31:349-67.

Coase, R. H. 1960. The Problem of Social Cost. Journal of Law and Economics 3:1-44.

Cooper, David J., and E. Glenn Dutcher. 2011. The Dynamics of Responder Behavior in Ultimatum Games: A Meta-Study. Experimental Economics 14:519-46. 
Croson, Rachel T. A., and Jason Scott Johnston. 2000. Experimental Results on Bargaining under Alternative Property Rights Regimes. Lournal of Law, Economics, and Organization 16:50-73.

Engel, Christoph, and Daniel Nagin. 2015. Who Is Afraid of the Stick? Experimentally Testing the Deterrent Effect of Sanction Certainty. Review of Behavioral Economics 2:405-34.

Falk, Armin, and Urs Fischbacher. 2002. "Crime" in the Lab: Detecting Social Interaction. European Economic Review 46:859-69.

Falk, Armin, and David Huffman. 2007. Studying Labor Market Institutions in the Lab: Minimum Wages, Employment Protection, and Workfare. Lournal of Institutional and Theoretical Economics 163:30-45.

Fischbacher, Urs. 2007. z-Tree: Zurich Toolbox for Ready-Made Economic Experiments. Experimental Economics 10:171-78.

Gilovich, Thomas, and Victoria Husted Medvec. 1995. The Experience of Regret: What, When, and Why. Psychological Review 102:379-95.

Güth, Werner, Rolf Schmittberger, and Bernd Schwarze. 1982. An Experimental Analysis of Ultimatum Bargaining. Journal of Economic Behavior and Organization 3:367-88.

Haisley, Emily C., and Roberto A. Weber. 2010. Self-Serving Interpretations of Ambiguity in Other-Regarding Behavior. Games and Economic Behavior 68:614-25.

Hoffman, Elizabeth, Kevin McCabe, and Vernon L. Smith. 2008. Reciprocity in Ultimatum and Dictator Games: An Introduction. Pp. 411-16 in vol. 1 of Handbook of Experimental Economics Results, edited by Charles R. Plott and Vernon Smith. Amsterdam: Elsevier.

Kahneman, Daniel, Jack L. Knetsch, and Richard H. Thaler. 1990. Experimental Tests of the Endowment Effect and the Coase Theorem. Lournal of Political Economy 98:132548 .

1991. Anomalies: The Endowment Effect, Loss Aversion, and Status Quo Bias. Lournal of Economic Perspectives 5(1):193-206.

Kaplow, Louis, and Steven Shavell. 1996. Property Rules versus Liability Rules: An Economic Analysis. Harvard Law Review 109:713-90.

Kelman, Mark. 1978-79. Consumption Theory, Production Theory, and Ideology in the Coase Theorem. Southern California Law Review 52:669-98.

Korobkin, Russell B. 2003. The Endowment Effect and Legal Analysis. Northwestern University Law Review 97:1227-91.

- 2014. Wrestling with the Endowment Effect, or How to Do Law and Economics without the Coase Theorem. Pp. 330-34 in The Oxford Handbook of Behavioral Economics and the Law, edited by Eyal Zamir and Doron Teichman. Oxford: Oxford University Press.

Köszegi, Botond, and Matthew Rabin. 2006. A Model of Reference-Dependent Preferences. Ouarterly Journal of Economics 121:1133-65.

Lewinsohn-Zamir, Daphna. 2012. The Questionable Efficiency of the Efficient-Breach Doctrine. Iournal of Institutional and Theoretical Economics 168:5-26.

Loewenstein, George, Samuel Issacharoff, Colin Camerer, and Linda Babcock. 1993. Self-Serving Assessments of Fairness and Pretrial Bargaining. Lournal of Legal Studies 22:135-59.

McClintock, Charles G., and Wim B. Liebrand. 1988. Role of Interdependence Structure, Individual Value Orientation, and Another's Strategy in Social Decision Making: A Transformational Analysis. Journal of Personality and Social Psychology 55:396-409. 
Montero, Maria, Martin Sefton, and Ping Zhang. 2008. Enlargement and the Balance of Power: An Experimental Study. Social Choice and Welfare 30:69-87.

Oosterbeek, Hessel, Randolph Sloof, and Gijs van de Kuilen. 2004. Cultural Differences in Ultimatum Game Experiments: Evidence from a Meta-Analysis. Experimental Economics $7: 171-88$.

Prudencio, Yves Coffi. 1982. The Voluntary Approach to Externality Problems: An Experimental Test. Lournal of Environmental Economics and Management 9:213-28.

Rachlinski, Jeffrey J., and Forest Jourden. 1998. Remedies and the Psychology of Ownership. Vanderbilt Law Review 51:1541-82.

Rammstedt, Beatrice, and Oliver P. John. 2007. Measuring Personality in One Minute or Less: A 10-Item Short Version of the Big Five Inventory in English and German. Lournal of Research in Personality 41:203-12.

Schildberg-Hörisch, Hannah, and Christina Strassmair. 2012. An Experimental Test of the Deterrence Hypothesis. Lournal of Law, Economics, and Organization 28:447-59.

Thaler, Richard H., Amos Tversky, Daniel Kahneman, and Alan Schwartz. 1997. The Effect of Myopia and Loss Aversion on Risk Taking: An Experimental Test. Quarterly Lournal of Economics 112:647-61.

Tversky, Amos, and Dale W. Griffin. 2000. Endowments and Contrasts in Judgements of Well-Being. Pp. 709-25 in Choices, Values, and Frames, edited by Daniel Kahneman and Amos Tversky. Cambridge: Cambridge University Press.

Tversky, Amos, and Daniel Kahneman. 1991. Loss Aversion in Riskless Choice: A ReferenceDependent Model. Quarterly Journal of Economics 106:1039-61. 